\title{
Use of Polypropylene Non-woven as Sorbent of Oil
}

\section{Small}

Luciano Peske Ceron ${ }^{1}$, Marcelo Zaro ${ }^{2}$, Kevin Pilger ${ }^{1}$, Thalles Augusto Brutti Marques ${ }^{1}$ and Pablo Copes Tonin ${ }^{1}$

1. School Polytechnic, Pontifical Catholic University of Rio Grande do Sul, Porto Alegre, Rio Grande do Su 90619-900l, Brazil

2. Department of Chemical Engineering, Federal University of Rio Grande do Sul, Tramandai, Rio Grande do Sul 95590-000, Brazil

\begin{abstract}
In this work, the mechanical tensile and elongation properties and the non-woven polypropylene flammability were evaluated, with variations of gratings, compared to non-woven fabrics prepared with thermo film and TNT (fabric non-fabric), for applications such as geotextile sorption of oil spills. The results showed high values of tensile strength for non-woven fabric prepared for application as geotextile, improving the mechanical properties of rupture.
\end{abstract}

Key words: Stretch, non-woven, polypropylene, sorption, traction.

\section{Introduction}

Barriers are used to inhibit the spread of oil in larger areas and prevent oil from reaching sensitive coastal areas as shown in Fig. 1. Some models absorb the oil in a mechanical effort to contain it. In other cases, controlled fires burn the water oil, although this creates another pollutant, or chemical dispersants are added to the water to accelerate the decomposition of the oil components [1].

Oil spills are critical because they are urgent and unexpected because of the enormous damage they cause to aquatic environments and marine life, so they must be contained quickly before they cause long-term disasters. Techniques to contain and recover the spilled oil are readily available in the form of barriers that collect it, but these seldom completely correct the problem [2].

Polypropylene (PP) is a branched polymer obtained by stereospecific polymerization via catalysis of the propene using the Ziegler-Natta catalyst [3, 4]. Melt spinning is one of the methods used to make non-woven PP blankets, where the polymer is melted and pumped through a matrix called spinneret with

Corresponding author: Luciano Peske Ceron, Ph.D., main research fields: environmental engineering. numerous small round holes. The melted fibers are cooled, solidified and collected in a take-up wheel, as shown in Fig. 2. The elongation of the fibers in both the liquid and solid favors the orientation of the PP chains along the fiber axis [4-6].

In the applications of sorbent materials with polypropylene (PP) non-woven, the mechanical properties of rupture and fatigue can be reinforced using thicker product or the compressibility of the blanket in the placement of thermo film and TNT [7, 8].

The adequate application of synthetic blankets used as sorbents in barriers to inhibit the propagation of oil leaks requires knowledge of the mechanical properties and flamability to characterize their behavior in industrial applications [9]. Thus, the behavior to the burning, traction and elongation of the hydrophobic material, shows that it is important to characterize the non-woven as a function of its weight [10]. The objective of this work was to analyze the mechanical properties of traction and elongation, and of flammability in non-woven PP with 300, 540 and 880 $\mathrm{g} / \mathrm{m}^{2}$ and compare with $740 \mathrm{~g} / \mathrm{m}^{2}$ blanket with thermo film and TNT, product used for spillage in oil spills.

The mechanical test of traction and elongation in non-woven was performed in the longitudinal and transverse directions, according to norm NBR 

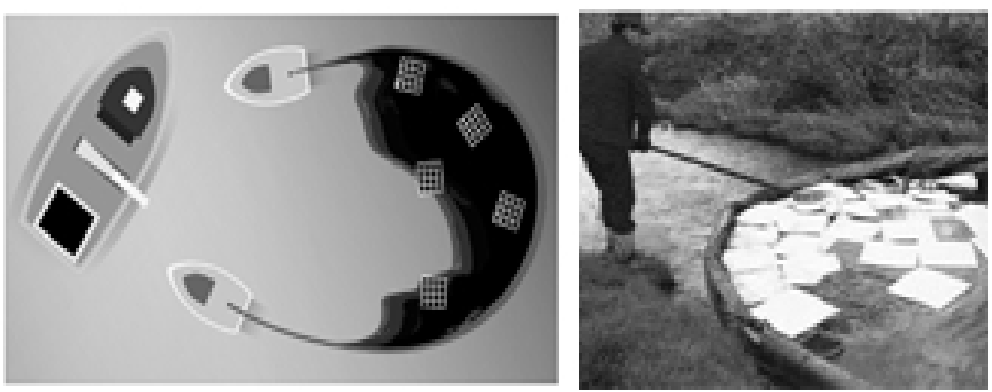

Fig. 1 The towed non-woven barrier, boats and oil catch.

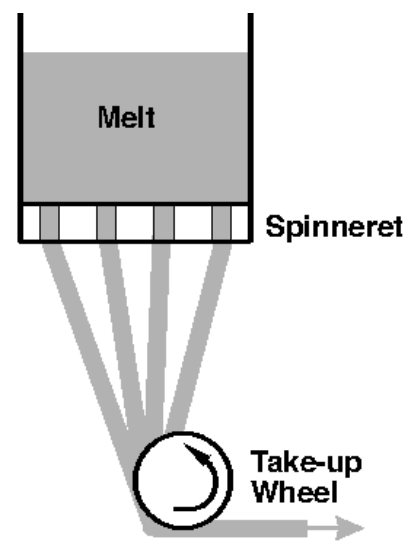

Fig. 2 Melt-spinning process.

13041:2004_Determination of tensile strength and elongation [12], which consist of applying the load until the body of evidence. The materials were conditioned for $24 \mathrm{~h}$ at $23 \pm 2{ }^{\circ} \mathrm{C}$ and $50 \pm 5 \%$ humidity before carrying out the test. Five specimens were used for each weight in each tensile test. The dimensions of the specimens in rectangular strip format were $50 \times 350 \mathrm{~mm}$, as shown in Fig. 4 .

\section{Experimental Setup}

The tests were carried out on non-wovens of PP produced by melt-spinning [11], provided by Ebios Tecnologia Ltda, located in Caxias do Sul, Rio Grande do Sul, Brazil. Four different types of mantas com 300,540 and $880 \mathrm{~g} / \mathrm{m}^{2}$ and another with $740 \mathrm{~g} / \mathrm{m}^{2}$ with term film and TNT.

\subsection{Fiber Characterization}

The characterization of the PP fiber used in the blankets (Fig. 3) was performed at the PUCRS Electronic Microscopy Center in a Philips scanning electron microscope device, model XL 30, with an acceleration voltage of $20 \mathrm{kV}$. The initial preparation of the specimens was performed in Bal-Tec Metallizer, Model SCD 005, by metallization with gold in the samples of non-woven fibers.

\subsection{Rechanical Resistance}

The equipment used for the non-woven mechanical tensile test was a universal test machine-Frank 81565 IV dynamometer, shown in Fig. 5. A constant vertical clearance velocity in the $100 \mathrm{~mm} / \mathrm{min}$ claw was applied with a load cell The results were obtained by a computer-linked NationalInstruments SC-2345 Series data system, which recorded the mechanical properties of traction and elongation.

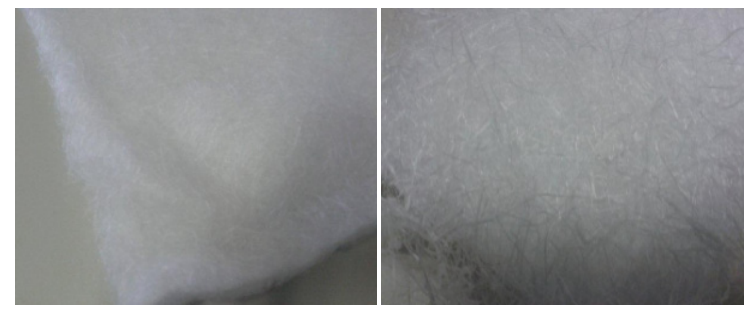

Fig. 3 PP blanket.

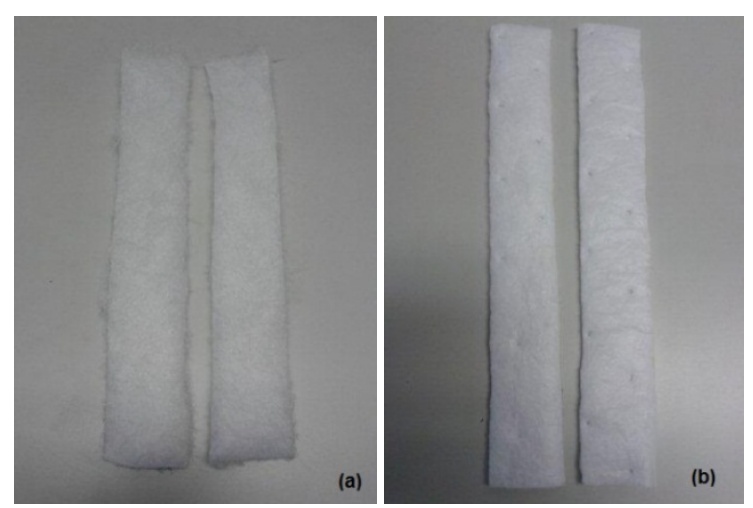

Fig. 4 PP non-woven test bodies. 


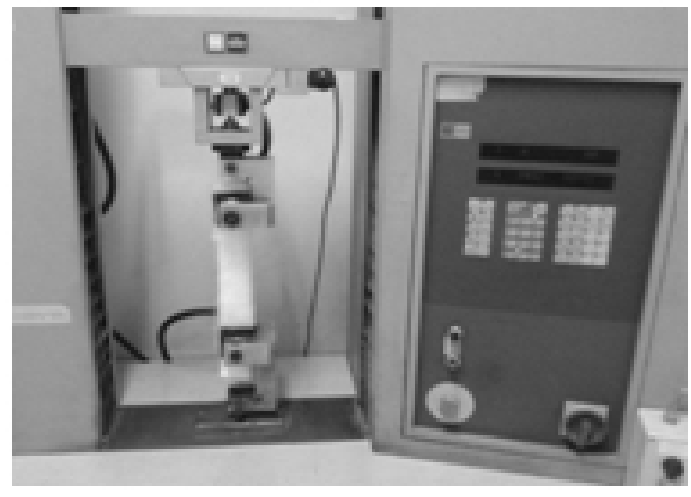

Fig. 5 Frank dynamometer.

\subsection{Flammability}

The principle of the test is to affix a sample to an appropriate U-shaped fastener inside a chamber (Fig. 6). The sample is exposed to the action of a flame defined as having a low energy content, and the flame must act on one of the free ends of the sample. The flame should come from a Bunsen burner, placed in the center of the lower corner of the sample opening, using LPG gas for burning (calorific value of approximately $38 \mathrm{MJ} / \mathrm{m}^{3}$ ).

The method follows NBR 14892: 2002-Non-woven-Flammability, which establishes as test condition the time of flame propagation in a certain area and sample weight, after exposure to a small flame, the area rate being determined.

\section{Results}

\subsection{Scanning Electron Miscroscopy}

The SEM micrograph (Fig. 7), identifies a disordered fiber interweaving, as well as the presence of individual fibers forming aggregates. Another consideration refers to the diameter of the fibers with many variations, which has a circular shape. These observations are a result of the method of production of the blanket, since more porous blankets siphon the oil faster, as shown by Wei, Q. F., ea al. [13].

Surface morphology varies from fiber to fiber, but generally exhibits a rough visual appearance surface. This detail is important because the more irregular the surface of a sorbent, the greater its surface area, which translates into a greater number of active sites for oil deposition [14].

\subsection{Traction and Stretching Test}

Table 1 and Fig. 8 show the mean values of the mechanical properties extracted from the tensile tests carried out on test bodies in the longitudinal and transverse directions.

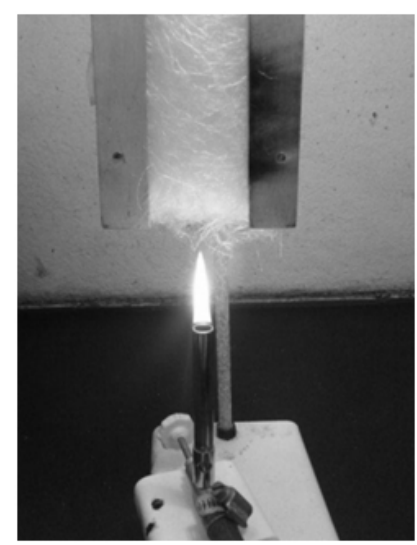

Fig. 6 Flammability test.
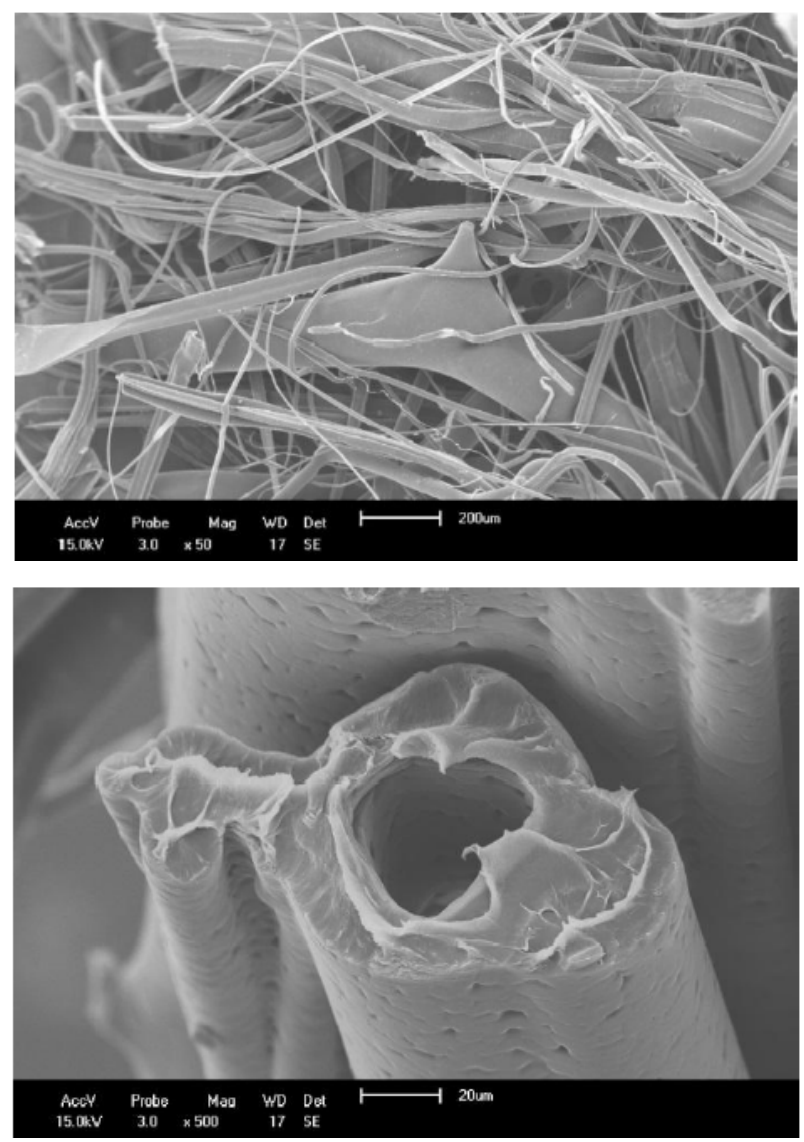

Fig. 7 SEM micrograph of PP fibers. 
Table 1 Results of mechanical properties of the tensile test.

\begin{tabular}{lcccc}
\hline Proof bodies & $\begin{array}{c}\text { Traction (N) } \\
\text { longitudinal }\end{array}$ & $\begin{array}{l}\text { Traction (N) } \\
\text { transverse }\end{array}$ & $\begin{array}{l}\text { Streth (\%) } \\
\text { longitudinal }\end{array}$ & $\begin{array}{l}\text { Streth (\%) } \\
\text { transverse }\end{array}$ \\
\hline $300 \mathrm{~g} / \mathrm{m}^{2}$ & $26.4 \pm 2.5$ & $20.2 \pm 1.2$ & $23.9 \pm 3.7$ & $22.8 \pm 2.8$ \\
$540 \mathrm{~g} / \mathrm{m}^{2}$ & $58.6 \pm 3.3$ & $56.1 \pm 3.5$ & $55.9 \pm 3.3$ & $29.3 \pm 3.1$ \\
$880 \mathrm{~g} / \mathrm{m}^{2}$ & $65.8 \pm 3.4$ & $61.8 \pm 4.1$ & $59.8 \pm 3.4$ & $35.4 \pm 3.6$ \\
$740 \mathrm{~g} / \mathrm{m}^{2}$ (term film and TNT) & $187.8 \pm 5.7$ & $88.0 \pm 4.8$ & $30.8 \pm 2.7$ & $27.3 \pm 4.3$ \\
\hline
\end{tabular}
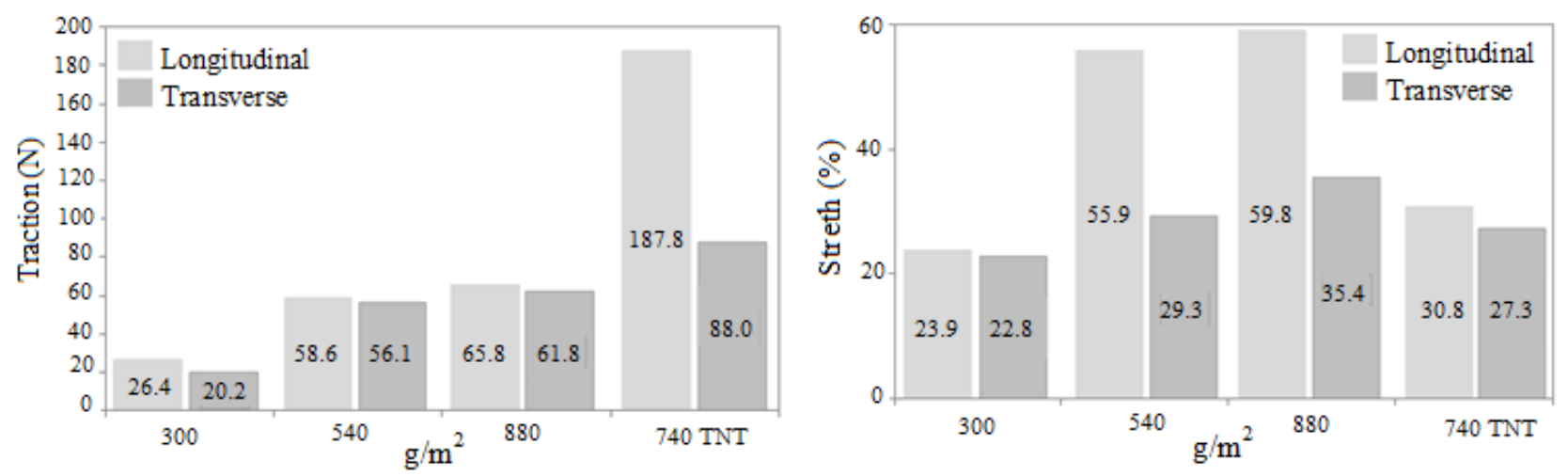

Fig. 8 Results of tensile strength and elongation (longitudinal and transverse directions).

There was a gradual increase in tensile strength as the weight rise from 300 to $880 \mathrm{~g} / \mathrm{m}^{2}$. Through the data, it is possible to justify the increase of the traction by the greater random distribution of fibers in the construction of the non-woven with a larger weight. As for the condition of higher traction results in the longitudinal direction, it is due to the non-woven production process, melt-spinning method, since the fibers are collected in the take-up wheel and thrown in this longitudinal preferred direction.

For the $740 \mathrm{~g} / \mathrm{m}^{2}$ composite film and TNT, material applied to the sorption of oils, there was a significant increase in traction in the longitudinal direction (187.8 $\mathrm{N}$ ), practically three times in relation to the material of $880 \mathrm{~g} / \mathrm{m}^{2}(61.8 \mathrm{~N})$. This increase occurred due to the compactness of the non-woven fibers, because in the placement of term film and TNT, material is fixed with folds to support the blanket in the application. Therefore, it is a significant reinforcement due to ruptures and fatigue in the material. In the transverse direction, the tensile increase occurred in the same proportion of elevation of the weight in the material, except for $740 \mathrm{~g} / \mathrm{m}^{2}$, where higher results were obtained as a function of the same conditions already mentioned above.

As in traction, the elongation at break is a property extremely dependent on the adhesion of the fibers in the construction of the non-woven. If adhesion is not perfect, voids occur and the material ruptures in the voids interface during the tensile test [15]. In this sense, in Fig. 8, there was a gradual increase of the elongation between 300 and $880 \mathrm{~g} / \mathrm{m}^{2}$ (in both dimensions - longitudinal and transverse), confirming the good compaction of the PP fibers during the production of the product. However, for $740 \mathrm{~g} / \mathrm{m}^{2}$, the value decreased due to the joining of different types of materials (PP fibers, thermofilm and TNT), occurring to the formation of voids in the joints of these materials.

\subsection{Flammability}

The results of the non-woven flammability tests of PP are presented in Table 2, with their respective area rates destroyed.

The rates of area destroyed by burning are practically constant close to $11.5 \mathrm{~cm}^{2} / \mathrm{s}$, so the weight of the PP blanket is not an impact factor, in case the material is burned in the application. 
Table 2 Flammability of PP.

\begin{tabular}{ll}
\hline Proof bodies & $\begin{array}{l}\text { Rate } \\
\left(\mathrm{cm}^{2} / \mathrm{s}\right)\end{array}$ \\
\hline $300 \mathrm{~g} / \mathrm{m}^{2}$ & $11.46 \pm 0.55$ \\
$540 \mathrm{~g} / \mathrm{m}^{2}$ & $11.80 \pm 0.45$ \\
$880 \mathrm{~g} / \mathrm{m}^{2}$ & $11.75 \pm 0.51$ \\
$740 \mathrm{~g} / \mathrm{m}^{2}$ (term film and TNT) & $11.33 \pm 0.39$ \\
\hline
\end{tabular}

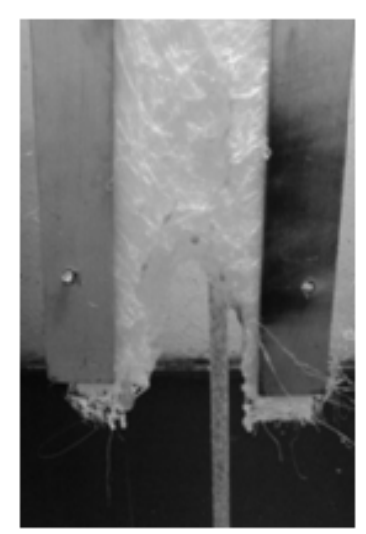

Fig. 9 Burned PP.

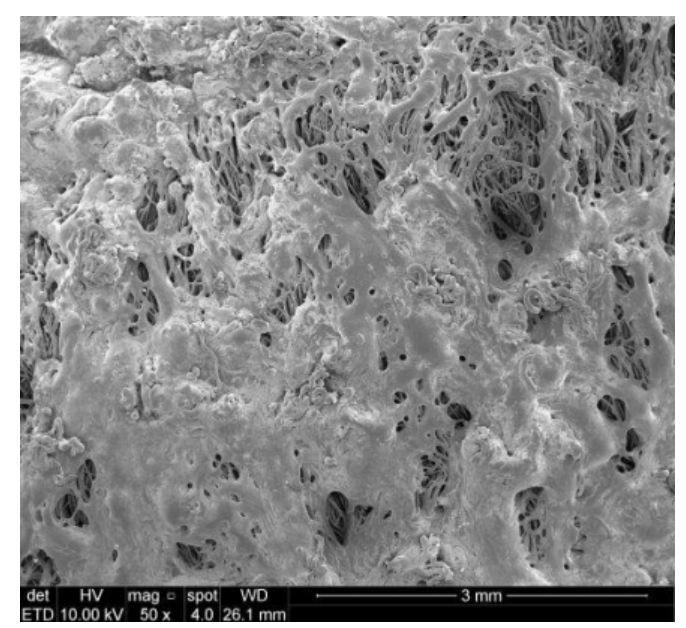

Fig. 10 Melt fiber SEM.

The non-woven PP obtained after the flammability test is shown in Fig. 9 and the scanning electron microscopy image of the PP fibers with characteristic of a plastic melt is shown in Fig. 10.

\section{Conclusion}

From the results obtained as a product in the oil sorption, it was found that application of thermofilmand TNT to the non-woven significantly improved the conditions of tensile strength of the material. In this context, increasing the useful life of the product in sorption applications for oils.
The elongation results for the same material weight evaluated in the longitudinal and transverse directions showed the greatest differences due to the non-woven production method with longitudinal preferential direction.

The firing rates are practically constant with respect to the various weights of the non-woven; it is not an impact factor in the application.

\section{References}

[1] Carver, L. 2016. Taking Care of Cleaning Oil Spills using Hydrophobic Meshes. Pittsburg: Consol News.

[2] Guimarães, S. T. L., Junior, S. C., Godoy, M. B. R. B., Tavares, A. C. 2012. Taking Care of Cleaning Oil Spills using Hydrophobic Meshes. Rio Claro: Printed in Brazil.

[3] Seymour, R. B., Cheng, T. 1987. Advances in Polyolefins. New York: Plenum Press.

[4] Shoemaker, J. 2006. Moldflow Design Guide: A Resource for Plastic Engineers. Munique: Hanser.

[5] Ehrlich, M., Becker, L. 2009. Reinforced Ground Walls and Slopes: Design and Execution. São Paulo: Texts Workshop.

[6] Moroni, L. G. 2005. Non-woven Manual: Classification, Identification and Applications. São Paulo: ABINT.

[7] Callister, W. D. Jr., Rethwisch, D. G. 2010. Materials Science and Engineering: An Introduction. EUA: Wiley.

[8] Sobczak, L. 1. R. W., Haider, A. A. 2012. "Polypropylene Composites with Natural Fibers and Wood-General Mechanical Property Profiles." Composites Science and Tecnology 72 (5): 550-57.

[9] Fiorentino, B., Fulchiron, R., Duchet, R. J., Bounor, L. V., Majesté, J. C. 2013. "Controlled Shear-induced Molecular Orientation and Crystallization in Polypropylene/talc Microcomposites Effects of the Talc Nature." Polymer 54 (6): 2764-75.

[10] Duc, A. L., Vergnes, B., Budtova, T. 2011. "Polypropylene/naturafibres Composites: Analysis of the Dimensions after Compounding and Observations of Fibre Rupture by Rheooptics." Composites Part A: Applied Science and Manufacturing 42 (11): 1727-37.

[11] Alfieri, P., ed. 2000. Textile Product Development: Executive in Fashion Business. São Paulo: Anhembi Morumbi.

[12] ABNT NBR 13041. 2002. Non-woven-Determination of Tensile Strength and Elongation.

[13] Wei, Q. F., Mather, R. R., Fotheringham, A. F., Yang, R. D. 2003. "Evaluation of Non-woven Polypropylene Oil Sorbents in Marine Oil-spill Recovery." Marine Pollution 
Bulletin 46: 780-83.

[14] Steffens, J., Coury, J. R. 2007. "Collection Efficiency of Fiber Filters Operating on the Removal of Nano-sized Aerosol

Fiber."
Separationand Purification 58 (7): 99-105.

[15] Caraschi, J. C., Leão, A. L. 2002. "Woodflour as Reinforcement of Polypropylene." Materials Research 5 (4): 405-09. 